\title{
Nurses' Attitudes Toward Patient Advocacy in Oncology Department University Hospital
}

\author{
Naglaa Abd El-Aziz El Seesy ${ }^{1, ~ *, ~ E l h a m ~ A b d a l l a h ~ A l ~ N a g s h a b a n d i ~}$ \\ ${ }^{1}$ Faculty of Nursing, Alexandria University, Alexandria, Egypt \\ ${ }^{2}$ Medical Surgical Nursing Department, King Abdulaziz University, Jeddah, Saudi Arabia
}

Email address:

nona20102002@yahoo.com (N. A. El-Aziz El Seesy)

${ }^{*}$ Corresponding author

\section{To cite this article:}

Naglaa Abd El-Aziz El Seesy, Elham Abdallah Al Nagshabandi. Nurses' Attitudes Toward Patient Advocacy in Oncology Department University Hospital. American Journal of Nursing Science. Vol. 5, No. 6, 2016, pp. 266-271. doi: 10.11648/j.ajns.20160506.15

Received: October 26, 2016; Accepted: November 8, 2016; Published: December 2, 2016

\begin{abstract}
The concept of patient advocacy has received international recognition over the last two decades. Although much researches has been done on nurses' attitudes in general, little has been done focusing particularly on oncology patient advocacy and almost no research was conducted in Saudi Arabian: The current study aimed to assess nurses' attitudes toward patient advocacy in oncology department University hospital. The study followed a cross-sectional descriptive design and was carried out in the oncology department at university hospital in Jeddah, kingdom of Saudi Arabian. All nurses $(\mathrm{n}=46)$ who were working in the previously mentioned units and willing to participate in study were included. All of them were responsible for providing direct health care to oncology patients. Data gathering tool used was the Attitude toward patient advocacy instrument which was developed by $\mathrm{Wu}$ and $\mathrm{BU}$ (2008) and adapted to measure nurses ' attitudes toward advocacy of oncology patients. It consists of three components of nurses attitudes 64 items. This study found that the mean percentage scores of the participants' overall attitudes toward oncology patients advocacy was relatively positive 82.06 (SD 5.61). The highest mean scores percentages of participants' attitudes were found on nurses response to acting on behalf of patients dimension 84.80 (SD 5.92), However, participants' attitude to championing social justice dimension of patient advocacy was the least item 79.59 (SD 6.49). Also, the results explains the relationship between nurses' attitudes and socio demographic characteristics. Nurses who were working in oncology wards had positive attitude toward patient advocacy. This study recommended incorporating patient advocacy in their curricula or designed programs. It is necessary to be included in the Saudi nursing student curriculum, and it should be continued for nurses to improve the quality of this role. In addition, encourage non Saudi nurses specifically, those from different cultural backgrounds to express their feelings toward patient advocacy. The study highlights important issues to be considered in hospital settings that recruit healthcare providers of diverse nationalities and support changes needed in the workplace setting to promote advocacy action for the patients' sake.
\end{abstract}

Keywords: Patient Advocacy, Oncology, Nurses, Attitude

\section{Introduction}

Cancer is considered one of the leading causes of death globally [1], estimated that around 7.6 million deaths cases (13\% of all deaths) occur worldwide and, It is predicted to be on the rise for the next few decades [2]. Cancer will rise to some 12 million deaths by 2030 [3]. In the Kingdom of Saudi Arabian (KSA) there is no exception, between January 01 and December 31, 2009, the total number of cancer incident cases reported the Saudi Council cancer Registry was 13,254
[4]. Every nurse, at some stage or another will take care of a patient diagnosed with cancer [5] and therefore nurses are challenged with meeting the needs of cancer patients and their families [6]. Therefore, Oncology nurses provide a focused patient centered care in assessing physical and psychosocial issues, and intervening to manage symptoms using their knowledge and critical thinking, that in turn supports patients and their families to manage and cope with diagnosis and treatment [7].

Nursing care of patients with cancer has been described as stressful, challenging and emotionally demanding [8], 
requiring advanced communication skills, counseling skills and specialist theoretical and practical knowledge through all stages of the cancer trajectory; from diagnosis, through treatment, potential recurrence, survivorship or possible death [6]. On top of all those demands cancer can cause vulnerability and compromise the patients' ability to selfdetermine their healthcare and protect their own best interests [9].

Advocacy is the essence of nursing's professional commitment to preserving human rights, protecting patients from harm and providing quality of care [10]. It is often considered to be a key nursing role, yet diverse definitions exist, causing confusion about the purpose of an advocate's role, which, in turn, makes it difficult to put advocacy into practice. Patient advocacy is an intrinsic essence of professional nursing ethics [11]. This ethical principle is vital to the nurse patient relationship and reveals a thought of reverence towards patients as human beings and towards patients' rights [12], [13]. Indeed, patients' needs or desires are recognized as a key impulsion for advocacy in nursing [14]. Many theorists describe the purpose of advocacy as defending and or promoting patients' rights. Willard (1996) describes how these rights may manifest as moral or legal [15].

Attitude is defined differently within the literature. According to the Business dictionary attitude is defined as a predisposition or a tendency to respond positively or negatively towards a certain idea, object, person, or situation. Attitude influences an individual's choice of action, and responses to challenges, incentives, and rewards (together called stimuli) [16]. Moreover, Breckler and Wiggins, (1992, p.409) defined attitudes as "mental and neural representations, organized through experience, exerting a directive or dynamic influence on behavior" [17]. It seems that from the two definitions, attitude is to think or act a certain way and anticipate reaction before it happens based on feelings.

The concept of advocacy has three core attributes which are; safeguarding a patient's autonomy, acting on behalf of patients, and championing social justice in the provision of health care. The first core attribute of advocacy is safeguarding a patient's autonomy that is concerned with actions, respect and promote a patient's self-determination. There are however, two caveats, patients must be competent and want to be fully informed and involved in their healthcare. This concept of advocacy can be described as being concerned with patients' legal rights. The second core attribute of nursing advocacy is acting on behalf of patients. This involves acting for patients who are unable to represent themselves or who do not wish to represent themselves such as patients who are unconscious would belong to this group. The third core attribute is championing social justice in the provision of health care. It is concerned with nurses actively striving to make changes to address inequalities and inconsistencies related to the provision of healthcare [18].

Although, plenty of researches has been conducted on nurses' attitudes in general, little has been done focusing particularly on oncology patient advocacy. However, there no studies have been found that examined nurses' attitudes towards patient advocacy in Saudi hospitals. Hence, this study will yield information on the nurses' attitudes toward the care of the oncology patient. It will also assess the relationship between certain demographics and nurses' attitudes on advocacy. The conclusions drawn from this study will be beneficial to nurses and nurse educators regarding care of the oncology patient as well as provides information on nurses' educational needs, both in the undergraduate curriculum and in continuing education within the healthcare institution. Additionally, nurses will be made aware of their own attitudes toward caring through this self-reflection, nursing care may be improved. The researchers hope is to use the study's findings to improve overall nursing care towards oncology patients. Knowing the nurses attitude in oncology units in relation to patient advocacy will help explore deficient areas, guide healthcare administrators and decision makers when planning policies. In addition, it will help nurse educators (at schools of nursing and in-service education offices) to focus more on the importance of patient advocacy in their curricula. Finally, conducting this study may shed light on the need for educational programs for further postgraduate education in the topics of patient advocacy.

\section{Material and Methods}

\subsection{Material}

\subsubsection{Design}

Descriptive cross sectional design was used in this study.

\subsubsection{Setting}

Data collected from the oncology department (medical and surgical as well as day care units) at a University Hospital in KSA.

\subsubsection{Subjects}

All nurses $(n=46)$ who were working in the oncology department (medical and surgical as well as day care units) and willing to participate in such study. All of the nurses were responsible for providing direct health care to oncology patients.

\subsubsection{Instrument: Attitude Toward Patient Advocacy Instrument}

The tool was developed by $\mathrm{Wu}$ and BU (2008) [19] and adapted to measure nurses ' attitudes toward advocacy of oncology patients. It includes 64 items categorized into three components of nurses attitude: safeguarding patients' autonomy (28 items), acting on behalf patients (17items), championing social justice (19 items). The responses were measured in four points Likert rating scale from strongly agree (4), to strongly disagree (1). The higher the score, the higher the attitude towards advocacy of oncology patients. In addition, data was collected on nurses' demographic and professional characteristics including work unit, age, sex, educational level, and total years of experience in the nursing field. 


\subsection{Methods}

The Ethics Committee of Faculty of Nursing, king AbdulAziz University has reviewed and approved the protocol of nurses ' attitude toward advocacy of oncology patients. Five experts in the same field of the study tested the questionnaire for content validity and the needed modifications were carried out. The reliability of the internal consistency was done using Cronbach's alpha for Attitude toward patient advocacy instrument and the result proved its reliability ( $\alpha 0$. 867 ), while the statistical significance level was set at $\mathrm{p}<$ 0.05 .

Before embarking on data collection, an informed consent was obtained from each participant to participate in the study. All participants were assured that their participation is voluntary, and their privacy and confidentiality were to be maintained.

A pilot study was carried out on 10 nurses who were working in the hospital units other than the studied units and the necessary modifications were made. The questionnaire was hand delivered to each participant in the morning and afternoon shifts and it was completed through self-report method. About 30 minutes were consumed to complete the questionnaire. Data collection took about four months and started from February until end of May 2015.

\subsection{Data Analysis}

After data was collected it was revised, coded and fed into statistical software SPSS IBM version 20. All statistical analysis was done using two tailed tests and alpha error of 0.05. All discrete scores for items concerning attitude were summed together and total score was obtained by simple summing. The score $\%$ for each dimension was calculated by dividing the actual score by the maximum score then multiplied by one hundred.

Different statistical tests were used in this study: descriptive statistics in the form of frequencies and percentages were used to describe the categorical data variables while scale data were expressed by mean/ mean percent and standard deviation. To test for association between sample characteristics and their attitude, independent samples t-test or one way ANOVA were used for comparing two items categories or more, respectively.

\section{Results}

\section{Background characteristics of the participants}

More than one third of the nursing staff $(44.4 \%)$ were in the age group from 30 to less than 40 with mean age of 41.7 +5.7 . It was found that more than half of them $(60 \%)$ were married. About $46.7 \%$ of participants had BSN. Also 35.6\% of nurses had from one to less than 15 years of experience in the nursing field. The majority of nursing staff $(91.1 \%)$ were Christian, compared to only $8.9 \%$ were Muslim. More than half of the nursing staff $(60 \%)$ were Indian compared with $40 \%$ which were Filipino. Moreover, $86.7 \%$ of participants attended patient rights orientation.

Table 1 indicates the mean score percentages of nursing staff' attitudes toward oncology patients' advocacy at a University hospital, where the mean percentage scores of the participants' overall attitudes toward oncology patients advocacy was relatively high 82.06 (SD 5.61). The highest mean scores percentages of participants' attitude were found on nurses response to acting on behalf of patients dimension 84.80 (SD 5.92), However, participants' attitude to championing social justice dimension of patient advocacy was the lowest item 79.59 (SD 6.49).

Table 1. Mean scores of nursing staff' attitudes toward oncology patient advocacy dimensions at a University hospital.

\begin{tabular}{|c|c|c|c|c|c|}
\hline Domain & $\alpha$-Cronbach's & Minimum\% & Maximum\% & Mean \% & SD \\
\hline Safeguarding patients' autonomy (SPA) & 0.952 & 68.75 & 93.75 & 82.06 & 6.49 \\
\hline Acting on behalf of patients & 0.886 & 66.18 & 95.59 & 84.80 & 5.92 \\
\hline Championing social justice & 0.846 & 65.79 & 92.11 & 79.59 & 6.49 \\
\hline Attitude total & 0.867 & 69.53 & 92.19 & 82.06 & 5.61 \\
\hline
\end{tabular}

Table 2 illustrates the relationship between mean percentage scores of total attitude of nursing staff toward oncology patients' advocacy at a University hospital and their socio demographic characteristics. This table indicated no significant relationship between attitudes and each of socio demographic as characteristics age, marital status, education, experience, attending patients' rights orientation, nationality and religion.

Table 2. Mean score percentages of overall nursing staff' attitudes toward oncology patient advocacy in relation to their demographic characteristics.

\begin{tabular}{|c|c|c|c|}
\hline \multirow{2}{*}{ Socio demographic data } & \multicolumn{2}{|c|}{ Attitude total } & \multirow{2}{*}{ Test (P) } \\
\hline & Mean & SD & \\
\hline \multicolumn{4}{|l|}{ Age (years) } \\
\hline $30-$ & 81.91 & 5.94 & \multirow{3}{*}{$\mathrm{F}=0.51(0.599)$} \\
\hline $40-$ & 81.39 & 6.14 & \\
\hline $50+$ & 83.84 & 3.32 & \\
\hline \multicolumn{4}{|l|}{ Marital status } \\
\hline Married & 81.61 & 6.20 & \multirow[t]{2}{*}{$\mathrm{t}=0.64(0.520)$} \\
\hline Divorced & 82.73 & 4.68 & \\
\hline \multicolumn{4}{|l|}{ Education } \\
\hline Diploma & 80.54 & 6.01 & $\mathrm{t}=1.91(0.091)$ \\
\hline $\mathrm{BSN}$ & 83.38 & 4.99 & \\
\hline
\end{tabular}




\begin{tabular}{|c|c|c|c|}
\hline \multirow{2}{*}{ Socio demographic data } & \multicolumn{2}{|c|}{ Attitude total } & \multirow{2}{*}{ Test (P) } \\
\hline & Mean & SD & \\
\hline \multicolumn{4}{|l|}{ Experience (years) } \\
\hline $1-$ & 81.76 & 4.89 & \multirow{3}{*}{$\mathrm{F}=0.35(0.707)$} \\
\hline $15-$ & 81.41 & 6.90 & \\
\hline $20-30$ & 83.09 & 5.10 & \\
\hline \multicolumn{4}{|c|}{ Attending patient rights orientation } \\
\hline Yes & 82.29 & 5.47 & \multirow[t]{2}{*}{$\mathrm{t}=0.71(0.481)$} \\
\hline No & 80.53 & 6.80 & \\
\hline \multicolumn{4}{|l|}{ Nationality } \\
\hline Filipino & 83.59 & 5.14 & \multirow[t]{2}{*}{$\mathrm{t}=1.5(0.135)$} \\
\hline Indian & 81.03 & 5.77 & \\
\hline \multicolumn{4}{|l|}{ Religion } \\
\hline Muslim & 84.28 & 1.95 & \multirow{2}{*}{$\mathrm{t}=0.83(0.413)$} \\
\hline Christian & 81.84 & 5.81 & \\
\hline
\end{tabular}

F: One Way ANOVA t: independent samples t-test $* \mathrm{P}<0.05$ (significant)

Table 3 shows the relationship between mean percentage scores of nursing staff' attitude dimensions toward oncology patient advocacy in relation to their demographic characteristics. There was no significant correlation difference between safeguarding patients' autonomy dimension of attitude and each of socio demographic characteristics; age, marital status, education, experience, nationality and religion. However, when it comes to religion, this table illustrates that there was significant difference between acting on behalf of patients' dimension of attitude and participants' religion, Muslim nurses had more mean percentage than those who are Christians. In addition, that there was no significant correlation between championing social justice dimension of attitude and each of socio demographic characteristics such as age, marital status, education, experience and religion. Furthermore, there was significant difference between the same dimension and participants' nationality where Filipinos had a higher mean percentage than Indian nurses toward championing social justice dimension.

Table 3. Mean scores percentages of nursing staff'attitudes dimensions toward oncology patient advocacy in relation to their demographic characteristics.

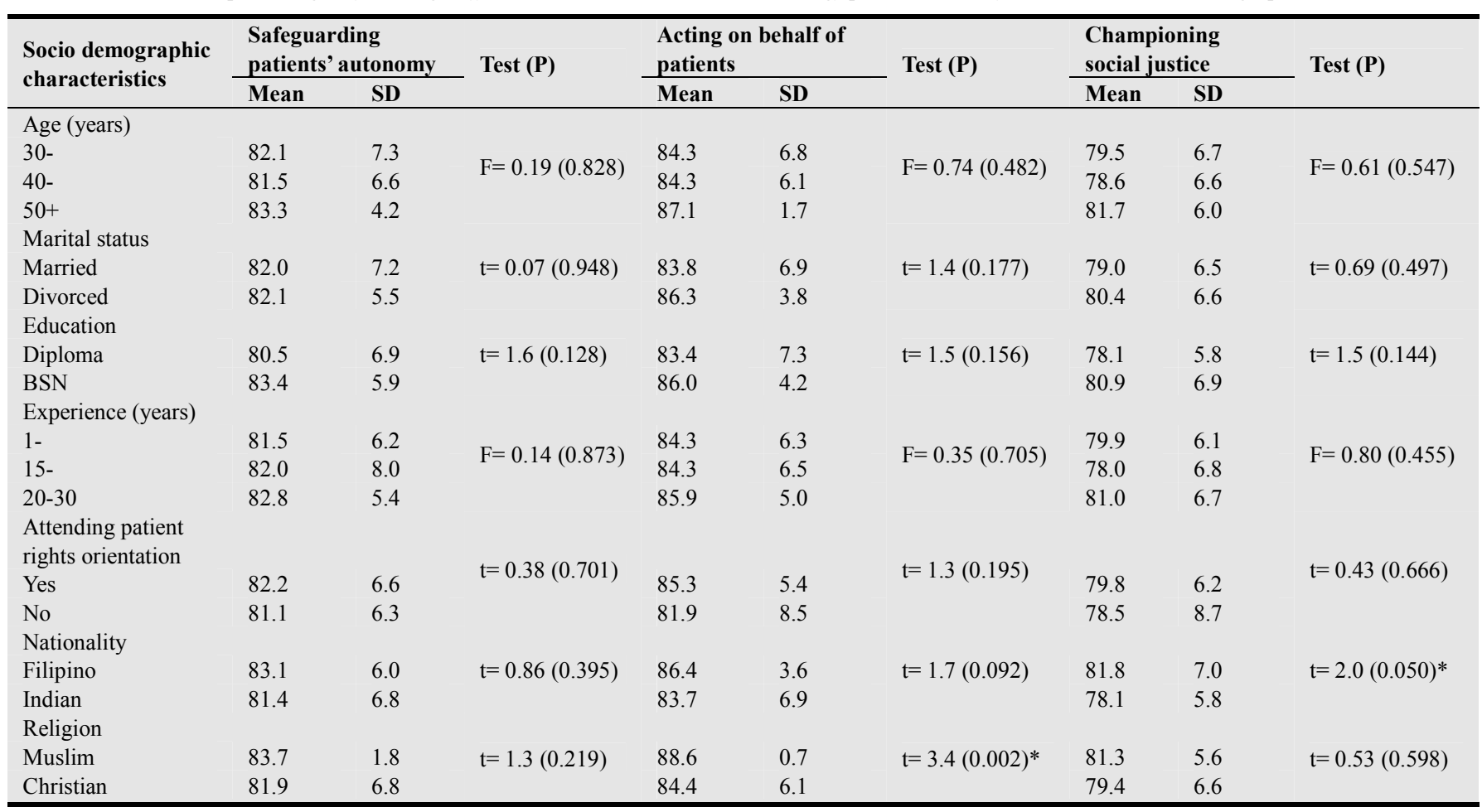

F: One Way ANOVA t: independent samples t-test $* \mathrm{P}<0.05$ (significant)

\section{Discussion}

The results of this study revealed that there was no significant relationship between overall attitude toward oncology patient advocacy and each of socio demographic characteristics age, marital status, education, experience, attending patient rights orientation, nationality and religion. This result is not in the same line with Mattiasson and Anderson (1995) [20] who found a positive correlation 
between education and advocacy. Similarly, Ingram (1998) reported that the nurses who attend ethics courses would engage more advocacy situations [21]. Furthermore, O'Connor and Kelly, (2005) reported that the ability to advocate was based on sound nursing knowledge and expertise [22].

Considering the religion of nurses working in the teaching hospital, although the number of Muslim nurses were small, it reflected a higher percentage mean toward acting on behalf of patient dimension than Christian nurses. Therefore, the significant difference might interpreted to the ability of Muslim nurses to communicate effectively with their Muslim patients and provide sensitive cultural and spiritual care. Islam, for Muslims in general and Saudis in particular, is not just a religious identity. Rather, it is central to life, guiding all aspects including personal, social, economic and political systems [23]. According to Rushton (1995), the compatibility of values and philosophy among various health care team members facilitate advocacy and patient outcome [24].

Nationality wise, both Indians and Filipino nurses were willing to strive to make changes to address inequalities and inconsistencies related to the provision of healthcare. Surprisingly, in this study, Filipino nurses were found to represent higher attitude toward championing social justice dimension of patient advocacy than Indian nurses. This is evident by less than $20 \%$ of nurses working in the public hospitals are Saudi citizens; the remaining $80 \%$ are expatriates from all over the world, mainly from other developing countries in the Indian Subcontinent and Southeast Asia [25]. According to Negarandeh et al, (2006) nurses 'ability to be patient advocators varied at different situations and settings. Nurses who could manage internal and external resources, might act better in patient advocacy [26].

Most importantly, this study indicated that nurses have a positive attitude toward oncology patient advocacy. This result could be explained in the light of the knowledge of expatriate nurses (Indians and Filipinos) about advocacy is sufficient and understandable, and this would lead to a positive attitude towards patient advocacy. The results of this study are supported by the previous studies conducted by Barrett-Sheridan, (2009) who had found positive nurses' attitude toward nursing advocacy [27].

The current study's respondents also reported that their attitude toward acting on behalf of patients dimension represented the highest mean scores percentages of participants' attitude. This could be due to an increase in admission rates of oncology patients who seeks the reputation of advanced specialized care of oncology services as well as professionalism exhibited by doctors and nurses and therefore acting on behalf of patients during their vulnerable period during admission to the hospital.

Acting on behalf of patients was translated in" representing patients" honoring wishes and reminding physicians and healthcare providers of patients' needs" [18]. As a result of the cultural variations between expatriate (Indians and Filipinos) nurses and Saudi patients, it seemed that nurses do act on behalf of patients rather than giving patients the chance of expression or self-determination. This finding was congruent with Negarandeh et al, (2006) who mentioned that limited communication, physicians leadings, lack of motivation and insufficient time to interact with patients and families were identified as barriers to advocacy [26]. Furthermore, the greatest obstacle to advocacy is the health care institution itself, because client advocacy is basically in conflict with the culture of the hospital system [28]. The work of Mutair, Plummer, O'Brien and Clerehan (2014) highlights the issues that non-Saudi nurses should be aware of when caring for Saudi patients and their families and emphasized that healthcare providers have a duty to deliver holistic and culturally competent health care, and that patients have the right to receive appropriate care from healthcare professionals. This task is made more difficult when non-Saudi nurses do not understand the Islamic principles and Saudi cultural beliefs and values [29].

However, participants' attitude to championing social justice dimension of patient advocacy was the least scored item in " nurses actively striving to make changes to address inequalities and inconsistencies related to the provision of healthcare". Most of the nurses who work in the teaching hospital agreed to examine institutional rules and policies and were are willing to support the legislations for people's health; however, some nurses stated that they were not in a position to have the authority to shape or change the policies. This is an area that needs to be addressed to strengthen the attitude toward championing social justice. Lack of authority and autonomy were highlighted as hindering factors for nursing advocacy [30]-[35]. Hence, it appears that the perceived sense of lack of authority and autonomy is partly self-induced and influenced by healthcare systems.

Limitations. The limitation of this study must be considered. Firstly, the sample size was relatively small limiting the generalizability of the study findings. Secondly, all study participants were non-Saudi. Therefore, as expatriate nurses they have limited authority to shape or change hospital policies and procedures. Thirdly, the study conducted in single institution.

\section{Conclusion and Recommendations}

It can be concluded that nurses who were working in oncology wards within the teaching hospital had positive attitude toward patient advocacy. The present study recommends education on nursing advocacy which is necessary to be included in the Saudi nursing student curriculum, and it should be continued to be enforced as continuous professional educational programs for nurses to improve the quality of this role. Additionally, dissemination of research study will brightly develop the identification of advocate role and support changes needed in the workplace setting to promote advocacy action for the patients' sake. Expatriate nurses specifically, from different cultural and religious backgrounds should be encouraged to express their feelings toward patient advocacy in KSA. 


\section{References}

[1] World Health Organization. (2014). Global Health Observatory Data Repository. Retrieved 12 May 2014 from: http://apps.who.int/gho/data/node.main.623.

[2] World Health Organization. (2010). Global status report on non-communicable diseases. Geneva, Switzerland.

[3] World Health Organization. (2011). Fact sheet $N^{\circ} 297$ World Health Organization, Geneva, Switzerland.

[4] Ministry of Health Saudi Cancer Registry. (2012). Cancer incidence report Saudi Arabia 2009. www.scr.org.sa.

[5] Kendall, S. (2007). Witnessing tragedy: Nurses' perceptions of caring for patients with cancer. International Journal of Nursing Studies, 13, 111-20.

[6] Wilkinson, S. (1999). Schering Plough clinical lecture communication: it makes a difference. Cancer Nurs, 22, 1720 .

[7] Hack F, Cummings G, Green E, Bultz, B, Fitzgerald B, McLeod D, Bottorff J. (2013). Comment Psychosocial care in oncology organizations collaborate to speed implementation on a global scale 12. (3,) august 2013, 10-12.

[8] Corner, J. (2002). Nurses' experiences of cancer. European Journal of Cancer, 11,193-9.

[9] Negarandeh, R, Oskouie F, Ahmadi F, \& Nikravesh M. (2008). The meaning of patient advocacy for Iranian nurses. Nursing Ethics, 15 (4), 454-67.

[10] Liske, C. (2015). Nurses attitude toward patient advocacy in long- term acute hospital setting Sigma Theta Tau international 43RD Biennial Convention, 7-11 November 2015 Lasvegas Nevada, USA.

[11] Jahromi M, Abbaszadeh A, Borhani F, Zaher H. (2012). Iranian nurses' attitudes and perception towards patient advocacy. International Scholarly Research Network, Volume 2012, 5 pages.

[12] Hem M, Heggen K. (2004). "Is compassion essential to nursing practice?" Contemporary Nurse, 17(1-2), 19-31.

[13] Snowball, J. (1996). Asking nurses about advocating for patients: "reactive" and "proactive" accounts. Journal of Advanced Nursing, 24, 67-75.

[14] Schroeter, K. (2000). Advocacy in perioperative practice. $A O R$ Journal 71 (6), 1207-1223 Webb, C. (1987). Speaking up for advocacy. Nursing Times, 83 (34), 33-5.

[15] Willard, C. (1996). The nurse's role as patient advocate: obligation or imposition? Journal of Advanced Nursing.24, 60-6.

[16] http://www.businessdictionary.com/definition/attitude.html Last retrieved on 23-12-2015.

[17] Breckler S, Wiggins E. (1992). On defining attitude and attitude theory: Once more with feeling. In A. R. Pratkanis, S. J. Breckler, \& A. G. Greenwald (Eds.) Attitude Structure and Function (pp. 407-427). Hillsdale, NJ: Erlbaum.

[18] Bu X \& Jezewski M. (2007). Developing a mid-range theory of patient advocacy through concept analysis. Journal of
Advanced Nursing, 57 (1), 101-10.

[19] $\mathrm{Bu} \mathrm{X,} \mathrm{Wu} \mathrm{Y.} \mathrm{(2008).} \mathrm{Development} \mathrm{and} \mathrm{psychometric}$ evaluation of the instrument: Attitude toward patient advocacy. Research in Nursing \& Health, 2008 Feb; 31 (1): 63-75.

[20] Mattiasson C, Andersson L. (1995). Moral reasoning among professional caregivers in nursing homes. West journal of nursing research, 17, 277-91.

[21] Ingram R. (1998). The nurse as the patient advocate.[http://www.richard.ingram.nhspeople.net/student/fil es/advocacy.pdf] University of Portsmouth, Department of Humanities. School of Social and Historical Studies. Accessed august 82003 .

[22] O'Connor T, \& Kelly B. (2005). Bridging the gap: A study of general nurses' perceptions of patient advocacy in Ireland. Nursing Ethics, 12, 453-67.

[23] Aldossary A, While A \& Barriball, L. (2008). Health care and nursing in Saudi Arabia. International Nursing Review, 55 (1), $125-8$.

[24] Rushtan H. (1995). Creating an ethical practice environment. Critical Care Nursing Clinic North America, 7, 387-97.

[25] Almutairi A \& Mccarthy L. (2012). A multicultural nursing workforce and cultural perspectives in Saudi Arabia: An overview. The Health, 3 (3), 71-4.

[26] Negarandeh R, Oskouie F, Ahmadi F, Nikravesh M \& Hallberg I. (2006). Patient advocacy: Barriers and facilitators patient advocacy for Iranian nurses. Nursing Ethics, 15 (4), 454-67.

[27] Barrett-Sheridan, S (2009). A Quantitative correlational study of political behavior and attitudes of nurses toward macrosocial patient advocacy, [D. H. A.], University of Phoenix, Phoenix, Ariz, USA.

[28] Konhne F (1982). Advocacy: Risks and reality. Mosby st, Louis.

[29] Mutair A, Plummer V, O'Brien P \& Clerehan R. (2014). Providing culturally congruent care for Saudi patients and their families. Contemporary Nurse, 46 (2), 254-8.

[30] Albarran, W. (1992). Advocacy in critical care, an evaluation of the implications for nurses and the future. Intensive Critical Care Nursing, 8 (1), 47-53.

[31] Donovan, C. (1989). Approaches to advocacy in cancer nursing- a revolution in care (Pritchard, A. P. Ed.). Proceedings of the fifth international conference on cancer nursing, London, 4-9 September 1988. McMillan Press Ltd, Basingstoke.

[32] Gillan, J. (1994). The right to know: The nurse's role in informing patients. Nursing Times, 90 (35), 46-7.

[33] Mallik, M. (1997). Advocacy in nursing - a review of the literature. Journal of Advanced Nursing, 25, 130-8.

[34] Melia, K. (1994). The task of nursing ethics. Journal of Medical Ethics, 20, 7-11.

[35] Schroeter, K. (2007). Advocacy: The tool of a hero. Journal of Trauma Nursing, 14 (1), 5-6. 